\title{
Characterization of light-absorbing carbon particles at three altitudes in East Asian outflow by transmission electron microscopy
}

\author{
J. Zhu, P. A. Crozier, and J. R. Anderson \\ School for Engineering of Matter, Transport and Energy, Arizona State University, Tempe, Arizona, USA \\ Correspondence to: P. A. Crozier (crozier@asu.edu)
}

Received: 21 November 2012 - Published in Atmos. Chem. Phys. Discuss.: 19 December 2012

Revised: 2 May 2013 - Accepted: 21 May 2013 - Published: 4 July 2013

\begin{abstract}
The morphology, microstructure, and composition of the submicron fraction of individual light-absorbing carbon (LAC) particles collected by research aircraft during the ACE-Asia (Asian Pacific Regional Aerosol Characterization Experiment) project above the Yellow Sea at altitudes of 120, 450 and $1500 \mathrm{~m}$ are investigated by transmission electron microscopy (TEM), and energy dispersive X-ray spectroscopy (EDS). Two types of carbonaceous particles, small spherule soot with graphitic spherules and amorphous carbonaceous spheres (brown carbon), are found at all altitudes in high concentration. For soot particles, emphasis of the study is on the component subparticles (spherules). The nanoscopic structures of the small spherule soot show no significant difference at three altitudes although the size distribution of primary spherules showed that $70 \%$ of the total volume lies in the ranges $30-50,50-85$ and $30-50 \mathrm{~nm}$, respectively. For the amorphous carbonaceous spheres, $70 \%$ of the total volume from three altitudes lies in the range 200-350, 160-470 and $150-320 \mathrm{~nm}$, respectively. Within the size fraction studied (submicron, with most particles in the range 50 to $500 \mathrm{~nm}$ ) the number concentration ratios of the amorphous carbonaceous spheres to primary spherules in soot at altitudes of 120 , 450 and $1500 \mathrm{~m}$ are about $1,1.5$ and 10 , respectively and their volume ratios are about 260, 50 and 1400. Lower relative concentrations of large spherule soot with intermediate graphitic structure were observed at $120 \mathrm{~m}$. Also, low relative number concentrations of carbon cenospheres were observed at 120 and $1500 \mathrm{~m}$. A key result of the study is that in vertically stratified outflow from East Asia, the character of LAC may have strong variance with altitude thus resulting in optical characteristics that vary with altitude. Also, apparent "aging" of LAC deduced from samples at multiple ground stations may instead reflect differences in the original carbon aerosols.
\end{abstract}

\section{Introduction}

Light-absorbing carbon (LAC, inclusive of black carbon, brown carbon and humic-like substances) has a strong impact on the global climate by modifying the radiative forcing effects of greenhouse gases and other forcing agents. Some studies have surmised that LAC could be the second strongest contribution to current global warming by directly absorbing solar and terrestrial radiation (Ramanathan and Carmichael, 2008). Other radiative forcing effects, such as the "semi-direct" effect of aerosols on cloud cover (Hansen et al., 1997), can be important in the presence of significant LAC concentrations. In such a case, cloud cover is suppressed and the warming effect is enhanced. However, the vertical distribution of LAC can be complex and the position of LAC layers is important. Koch and Del Genio (2010) presented a review of a number of studies that consider the complexities that may arise from different vertical distributions of LAC and suggest that in some cases there may be a net negative semi-direct effect that can partially (or even perhaps entirely) offset the warming effect of direct absorption. Clearly both the vertical distribution and optical properties of LAC are important for the net forcing. Spracklen et al. (2011) have discussed the possible role of LAC as cloud condensation nuclei (CCN) such that they also cool the climate by increasing cloud albedo. Whether this indirect forcing is regionally or globally important depends upon the extent to which LAC activate as CCN. Studies of important areas of marine stratiform clouds that have examined cloud droplet residues with electron microscopy have shown that LAC is not generally important as CCN because both size and composition are important (Twohy and Anderson, 2008) including in heavily polluted marine areas (Twohy et al., 2001; Hawkins et al., 2008). However, results of Stith et al. (2011) suggest that LAC from biomass burning may at times be important as ice

Published by Copernicus Publications on behalf of the European Geosciences Union. 
nuclei for cirrus, although the LAC in this case is mostly internally mixed with other components so that the results are perhaps ambiguous. In any event, there are not enough data to evaluate any possible negative forcing due to LAC influence on indirect effects through cloud albedo.

The net radiative effect of LAC results from their multiple roles. Black carbon, of which soot is but one type, is estimated to contribute somewhere in the range of $10-50 \%$ of the total tropospheric particulate matter (Zhang et al., 2008). After LAC are emitted to the atmosphere, they are subjected to aging processes such as absorption or condensation of gaseous species (Wyslouzil et al., 1994; Saathoff et al., 2003) and mixing with other aerosols, and oxidation (Liu et al., 2010; Lary et al., 1997; Rodriguez-Fortea et al., 2007). Processes, such as ice nucleation, cloud droplet formation (or scavenging) and gas degradation, would modify the structure and properties of the aerosols (Zhang et al., 2008).

There are numerous kinds of LAC with different morphology and structure. This diversity comes from variations in the combustion source, differences in combustion conditions and aging processes undertaken in the atmosphere. The LAC from the combustion of different sources, such as biomass, coal, and gasoline have their own morphological, structural and compositional fingerprints. For example, LAC from biomass that usually carries minerals (Zhu et al., 2012c) contain potassium (Li et al., 2010). Variation in combustion conditions, such as the combustion temperature, pressure, and amount of oxygen, may also lead to different types of LAC. In addition, those LAC will be subjected to different aging processes once they enter the atmosphere. The combination of source combustion conditions and atmospheric aging processes undertaken can result in LAC with a variety of morphologies and properties. Black carbon is a strong absorber of light across a wide range of wavelengths of the solar spectrum. Brown carbon, a type of LAC attracting recent attention, has modest absorption in the visible spectral region and an enhanced absorption towards the near-UV spectral region (Alexander et al., 2008). Besides optical properties, the chemical properties of different aerosols can also vary. Soot shows good catalytic properties for transforming $\mathrm{NO}_{2}$ into HONO in the presence of solar radiation (Monge et al., 2010).

Optical differences between LAC types arise from their different structures, size, morphology, aggregation state and compositions. The notable difference in soot and brown carbon is likely related to their graphitic and amorphous structures and compositional differences. Even for graphitic soot, microphysical processes, such as the ice nucleation on soot particles (Gorbunov et al., 2001), depends on the nanoscopic structure. Due to source effects, the local configuration of the graphene sheets in the soot varies significantly so it is necessary to describe these differences. A basic structural unit (BSU) has been developed (Chen et al., 2005) to characterize different graphene configurations. The BSU is described in terms of several indices that include the number of the stacking layers of graphene (layer No.), length of the stacking layers $(L a)$, thickness of the stacking layers $(L c)$ and the $d$-spacing of the stacking layers $\left(d_{0002}\right)$.

In addition, it is necessary to understand the distribution and the structural differences in LAC with altitude. The aerosols at different altitudes may originate from different sources and have histories. In the case of stable stratification, local sources will contribute most strongly to the boundary layer. Of course if strong convective mixing has occurred then the vertical distribution of aerosols will be more complex. For the samples discussed here, vertical profiles of temperature and relative humidity indicated stable stratification. In such a case, aerosols in higher stable layers may be transported from significant distances. Arimoto et al. (2006) reported that the Asian dust collected below about $2 \mathrm{~km}$ altitude during ACE-Asia (Asian Pacific Regional Aerosol Characterization Experiment) was commonly mixed with carbonaceous pollutants. However, there are limited studies on the size distribution of LAC, which could lead to uncertainty of the roles of the LAC such as the CCN (Pierce et al., 2007). It is important to analyze the relative concentrations of different types of LAC with altitude as the aerosols are typically treated in climate models as uniform in optical properties at all altitudes. However, a detailed study about individual LAC particles including their structure and composition is difficult and has not been widely attempted. It is important to characterize the nanoscale structure of LAC recorded at different altitudes to develop a fundamental understanding of their role in climate.

Transmission electron microscopy (TEM) is capable of providing local information on the structure, morphology and composition of LAC down to the nanoscale level (Chen et al., 2005). In our previous work, the optical properties of individual brown carbon aerosols collected above the Yellow Sea were studied in the TEM using monochromated electron energy-loss spectroscopy (Alexander et al., 2008). In the present work, the morphology, size, and structure of the LAC collected from the same region are analyzed by TEM imaging and energy dispersive X-ray spectroscopy (EDS).

\section{Experimental: sampling and characterization}

The samples were collected during the spring 2001 ACEAsia project. The specimens analyzed here were sampled on 25 April 2001 during flight RF14 of the NCAR C-130 aircraft over the Yellow Sea. The inlet used on the NCAR C-130 was a low-turbulence inlet (LTI) described by Huebert et al. (2004) and was controlled by a dedicated operator to maintain both isokinetic flow and the desired low turbulence conditions. The LTI was optimized to collect particles with diameters up to about $10 \mu \mathrm{m}$ and in fact tended to enhance the largest supermicron sizes. The absolute concentrations of brown carbon and dust are calculated from 
polycarbonate filter samples identical to those discussed by Huebert et al. (2004) and used to characterize the LTI.

The samples were collected from altitudes of 120, 450 and $1500 \mathrm{~m}$ within a stably stratified lower troposphere. The stratification was defined by parameters such as relative humidity (RH) and aerosol characteristics such as CCN concentrations and light scattering measured in real time during vertical profiles; it is possible that the various aerosol layers came from different source areas and had separate aging histories. The lowest altitude, $120 \mathrm{~m}$, was within the marine boundary layer (MBL) as indicated by high ambient RH (up to $76 \%$ ) and likely to be strongly influenced by local pollution including abundant ships and fishing boats observed from the NCAR C-130. Lower RH values (around 30\%) for the two higher layers indicate continental origin so the aerosols were not influenced by ship emissions. The sampling times were 18, 26 and $18 \mathrm{~min}$ for 120,450 and $1500 \mathrm{~m}$ altitudes, respectively. Results from the previous flight, RF13, on 23 April (Alexander et al., 2008), and some average data for multiple flights including RF-13 during ACE-Asia are discussed by Clarke et al. (2004) with data from a variety of instruments, including bulk optical measurements. RF-13 was the leading moist, warm side of a cold front and RF-14 on the trailing dry, cool side. Strong variation in a wide range of parameters with altitude was encountered on all the flights. However, the range of black carbon and brown carbon types observed by SEM (scanning electron microscopy) were similar. SEM images of LAC from RF-13 are included in Clarke et al. (2004).

A three-stage microimpactor (California Measurements, Inc. Model MPS-3) was used to collect the TEM samples. Supermicron particles were collected on stage 1 and are not discussed here. The nominal $50 \%$ cut aerodynamic diameter range for stage 2 was 0.3 to 2 microns and for stage 3, 0.05 to 0.3 microns. Because of the differences in morphology and density between standard spheres and the LAC particles collected, the cut sizes in practice could be quite different (the approximate upper cut size for stage 3 seemed to be about 0.5 microns). The results presented here are primarily from stage 3. We performed SEM observations of single-stage filter samples for which absolute number concentrations of most particles types, including brown carbon, were determined over the entire size range up to about 10 microns. We did not measure absolute concentrations of graphitic spherules in soot by SEM but can use the relative concentrations of brown carbon and graphitic spherules determined by TEM to estimate the concentrations of the latter. The silicate dust particle concentrations discussed later were determined using the automated SEM methods of Anderson et al. (1996) while the brown carbon concentrations were determined with manual SEM observations. A $200 \mathrm{kV}$ Schottky field emission analytical transmission electron microscope (JEOL JEM-2010F) equipped with thin window light element sensitive X-ray detector was used for the analysis of individual particles. Bright field imaging was used to detect the particle distribution, size, morphology, aggregation and mixing states. High resolution images were collected to study the microstructure of each particle. EDS was used to determine the elemental composition of individual particles with sensitivity for elements down to carbon. In order to maintain the initial status of the aerosol particle, and avoid radiation damage, low dose methods were adopted. During searching for and focusing on a sample area, the total electron dose was about $10^{3}$ electrons per $\mathrm{nm}^{2}$. For collection of normal images, the electron dose was about $10^{3}-10^{4}$ electrons per $\mathrm{nm}^{2}$. For high resolution images, the electron dose was about $10^{6}$ electrons per $\mathrm{nm}^{2}$. Microscope alignment and focus adjustment were performed on areas of the sample adjacent to the particles of interest so that the particles were not irradiated. However, to get adequate signal-to-noise in the EDS, the electron beam was focused on the target particles. Acquisition times were typically $10 \mathrm{~s}$ to achieve adequate statistics in the spectra and the spectra were always collected after imaging.

The BSU of the soot spherules was measured from the high resolution TEM (HRTEM) images from 8 locations within spherules. The $d$ spacing of (0002) plane $\left(d_{0002}\right)$, and the stacked layer length $(L a)$, the number of the layers (Layer No.) of the BSU of the soot spherules were measured to compare the soot from the three altitudes.

The TEM grid used for the $120 \mathrm{~m}$ altitude sample was a holey carbon film, while, for 450 and $1500 \mathrm{~m}$ samples, the grids were covered by a continuous carbon film. In order to check the thickness of the amorphous carbon spheres on a continuous carbon film, Beer's absorption law, $I_{t}=I_{0} e^{(-\alpha t)}$, was used to investigate the intensity variation with particle thickness $(t)$ for the imaging conditions employed. This was necessary to rule out significant shape deformation when the particles impacted the carbon support film and validate our assumption that the particles were essentially spherical in shape. Here, the intensity $I_{t}$ and $I_{0}$ are the intensity integrals of an area of $20 \times 20$ pixels in the center of the spheres and from the background in TEM images, respectively. Before using $t=1 / \alpha \cdot \ln \left(I_{0} / I_{t}\right)$ to calculate the thickness of the amorphous carbon spheres, the absorption coefficient $(\alpha)$ was determined from their TEM images of spheres suspended in vacuum on a holey carbon grid $(120 \mathrm{~m}$ sample). The spheres overhanging the vacuum should not show significant deformation. Their thicknesses are equal to their diameters and $\alpha$ was determined by $\alpha=1 / t \cdot \ln \left(I_{0} / I_{t}\right)$. Then the thickness of the particles on the grid with a continuous carbon film (450 and $1500 \mathrm{~m}$ samples) were determined by $t=1 / \alpha \cdot \ln \left(I_{0} / I_{t}\right)$.

\section{Results and discussion}

These samples contain a variety of particle types including soil dust (dominated by silicate minerals), ammonium sulfate and LAC. The relative and absolute concentrations of key particle types are discussed in Sect. 3.4. Because the air 
masses sampled were behind a cold front moving SE from mainland China, the dust at all levels and the LAC at the two higher levels likely originate from there. Some of the LAC in the marine boundary layer sample may be from local pollution such as fishing vessels. There are two main types of LAC found at all three altitudes: graphitic soot and amorphous carbonaceous spheres similar to the brown carbon spheres described by Alexander et al. (2008). Their morphology, structure, composition and size distribution will be discussed in the following sections. Before giving a full description, three low magnification TEM images from three different altitudes are given in Fig. 1 to show an overview of the typical morphology and distribution of the aerosol on the TEM grids. Many of the aerosol particles are spherical in shape. Some of the soot and amorphous carbonaceous spheres are marked by black and white arrows, respectively, in Fig. 1. For the altitude of $120 \mathrm{~m}$, there is a high density of particles on the carbon support. In later sections, we will also show that most of the soot at altitude of $120 \mathrm{~m}$ is attached on other types of particles. The more spherically shaped large particles with size of about $100-300 \mathrm{~nm}$ are mostly amorphous carbonaceous spheres.

\subsection{Soot}

The TEM analysis shows that the soot from the three altitudes consists of primary small spherules in the size range $15-100 \mathrm{~nm}$. Typical higher magnification TEM images of soot collected from altitudes of 120,450 and $1500 \mathrm{~m}$ are shown in Figs. 2, 3 and 4 respectively. The outer boundary of a spherule is identified by the outer most graphene sheet belonging to each spherule. The diameter is then taken as the distance between the outer boundary on opposites sides of the spherule.

At $120 \mathrm{~m}$ altitude, the primary spherules of soot are in the range of 20-70 nm. As shown in Fig. 2a, the soot spherules are aggregated together and have a turbostratic structure with multiple nuclei (Fig. 2b). The primary spherules, which can be discerned with separate boundaries from each other, are shown in Fig. 2a and b with dashed white lines. As shown in Table 1, the $d$ spacing of (0002) plane $\left(d_{0002}\right)$ of the soot spherules is in the range of $0.37-0.46 \mathrm{~nm}$, which is bigger than the $d_{0002}$ plane of graphite of $0.34 \mathrm{~nm}$, and even larger than $0.37-0.38 \mathrm{~nm}$ of soot particles prepared in a research lab (Chen et al., 2005). The stacked layer length ( $L a)$ of each BSU is about $1.04-2.39 \mathrm{~nm}$ and the number of the layers in each BSU is in 3-6. The EDS result (Fig. 2e) reveals that in addition to being mostly carbon, the soot had trace amounts of silicon, sulfur and potassium. No other element was detected other than copper, which comes from the $\mathrm{Cu}$ TEM grid. It should be noted that small silicon peaks have been observed as a possible contaminant in similar samples from other projects in which we have participated, so some uncertainty exists in cases where silicon concentrations are low. Most of the soot spherules at this altitude are internally

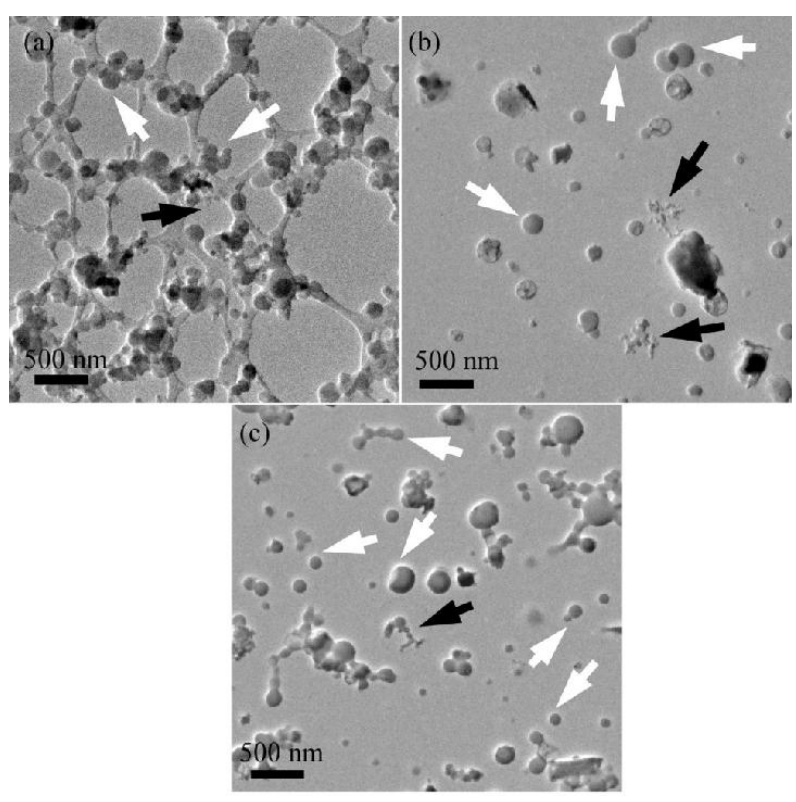

Fig. 1. TEM images of aerosols from (a) 120, (b) 450 and (c) $1500 \mathrm{~m}$ altitudes. Small spherule soot and brown carbon spheres are marked by black and white arrows, respectively.

Table 1. Parameters for the BSU of soot spherules in three altitudes, Layer No. range, $L a$ and $d_{0002}$ are range in number of graphene layers, length and the $d$ spacing of the stacking layers inside BSU, respectively.

\begin{tabular}{lllll}
\hline $\begin{array}{l}\text { Altitude } \\
(\mathrm{m})\end{array}$ & & $\begin{array}{l}\text { Layer No. } \\
\text { range }\end{array}$ & $L a(\mathrm{~nm})$ & $d_{0002}(\mathrm{~nm})$ \\
\hline 120 & & $3-6$ & $1.04-2.39$ & $0.37-0.46$ \\
450 & Spherical & $2-4$ & $0.67-1.27$ & $0.41-0.53$ \\
& Non-spherical & $3-4$ & $0.72-1.49$ & $0.34-0.45$ \\
1500 & & $3-5$ & $0.95-1.63$ & $0.40-0.46$ \\
\hline
\end{tabular}

mixed with amorphous carbon. As shown in Fig. 2c and d, two soot spherules are attached to the surface of larger amorphous carbonaceous particles. A detailed characterization of this amorphous carbon will be discussed in later sections.

Figure 3 shows the TEM images of soot collected from the intermediate altitude, $450 \mathrm{~m}$. The soot spherules are in the range of $20-100 \mathrm{~nm}$ and can be grouped into two categories, spherical (Fig. 3a, b), and non-spherical (Fig. 3c, d) subparticles. The individual soot particles are aggregates composed of either spherical or non-spherical subparticles, but not both. The spherical subparticles often with onion-like structure have a size range of $40-100 \mathrm{~nm}$, and contact each other by point to point contact. The non-spherical subparticles with turbostratic structure and multiple nuclei, fused together, have a diameter range of $20-40 \mathrm{~nm}$, similar to those found at $120 \mathrm{~m}$ (Fig. 2a). For the microstructure of those two kinds of soot spherules (Table 1), the layer number ranges of the spherical and non-spherical particles are 2-4 and 3- 

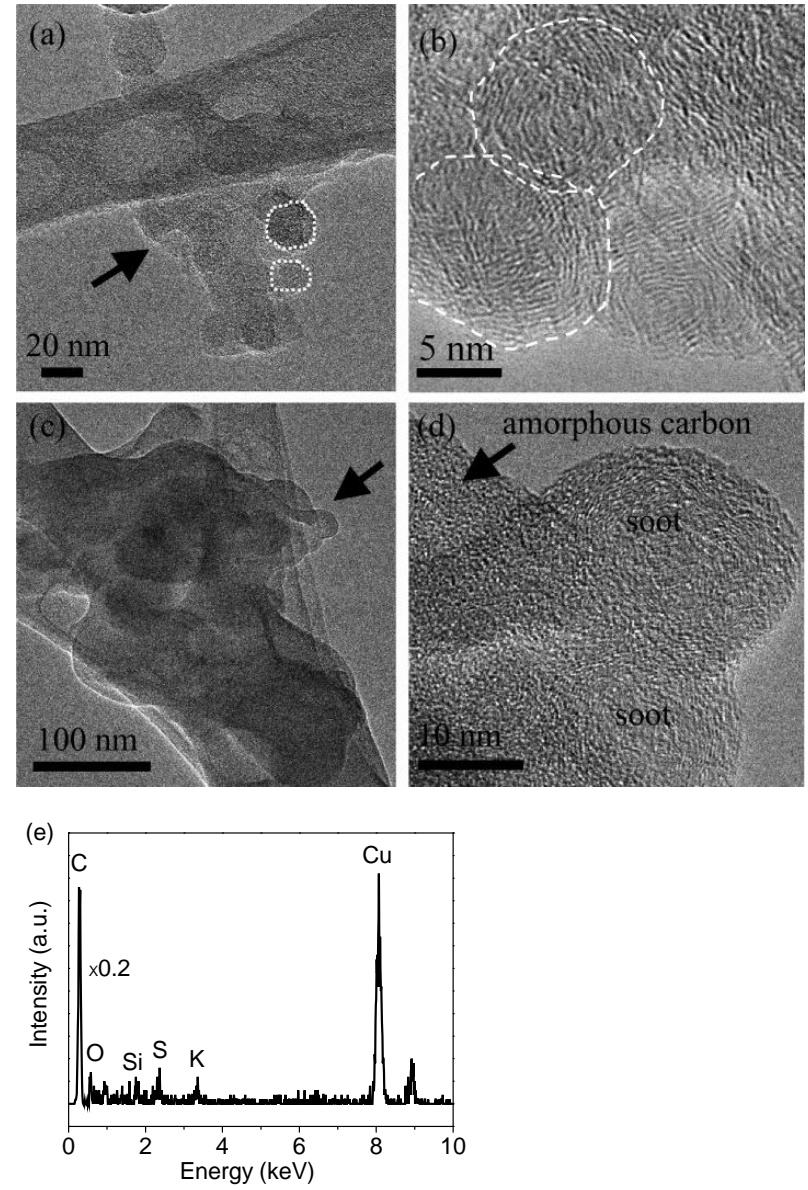

Fig. 2. Soot collected at $120 \mathrm{~m}$ altitude. (a) TEM image of a soot aggregate attached on carbon film and (b) HRTEM image from the arrowed area. (c) Soot spherules attached on amorphous carbon and (d) their HRTEM image from the arrowed area. (e) EDS results from the soot in image (a). The intensity of carbon peak is multiplied by factor of 0.2 for comparison with the weak signals from other elements.

4, respectively. Their $L a$ values are $0.67-1.27$ and $0.72-$ $1.49 \mathrm{~nm}$, respectively. Their $d$ spacings are about $0.41-0.53$ and $0.34-0.45 \mathrm{~nm}$, respectively. Typical EDS (Fig. 3e, f) collected from the two kinds of soot show that the atomic percentages of carbon, oxygen and silicon in spherical soot are approximately 99.5, 0.3 and 0.2 , respectively and those values in nonspherical soot are 95, 4 and 1, respectively. The spherical soot contains less silicon and oxygen than that of non-spherical ones.

The differences in morphologies and aggregation of the spherical and non-spherical subparticles may arise from different source conditions and/or atmospheric aging processes although it is perhaps difficult to imagine how aging would alter the fundamental internal structure of a spherule. The difference concerning point of contact or fusing between the subparticles is most likely to be associated with different
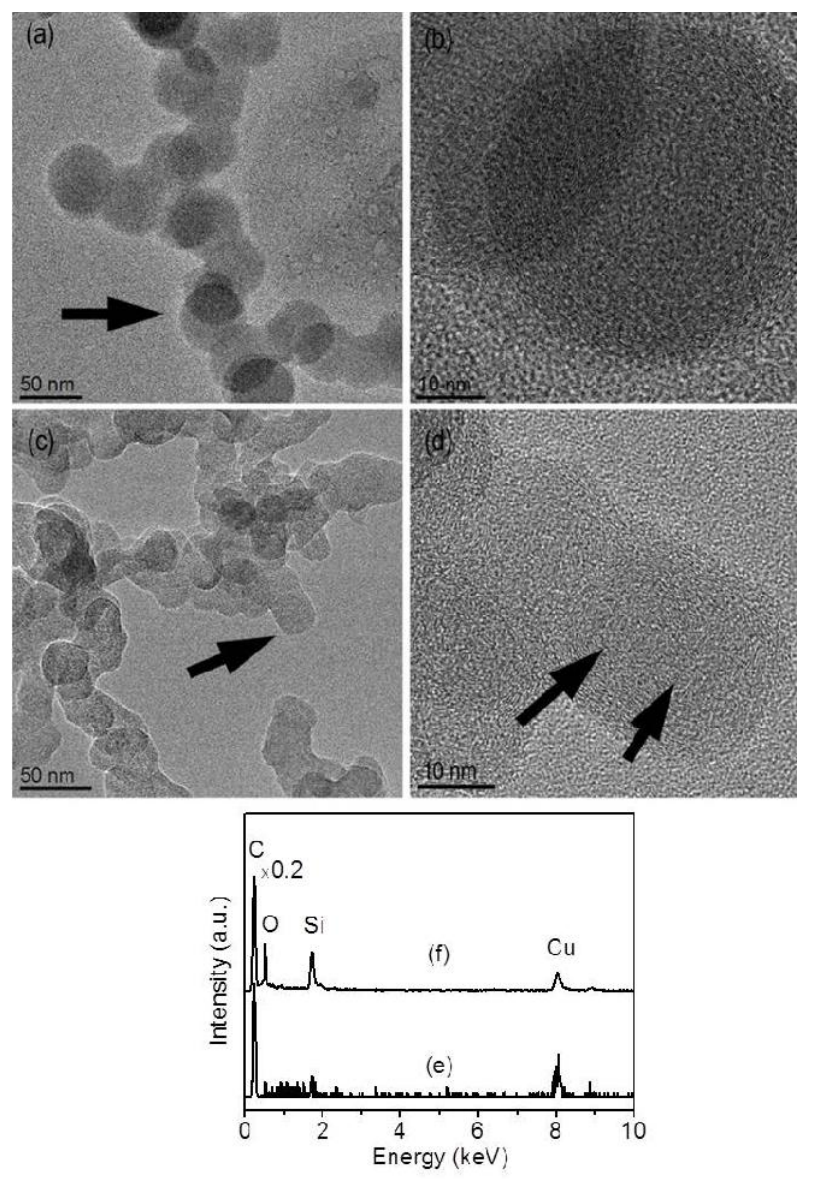

Fig. 3. TEM images of samples collected at $450 \mathrm{~m}$ altitude, (a) soot of spherical subparticles (spherules) and (b) their HRTEM image from the arrowed area, (c) soot of non-spherical subparticles and (e) their HRTEM image from the arrowed area. EDS results $(\mathbf{e}, \mathbf{f})$ from the soot in image (a, c), respectively. The intensity of the both carbon peaks in (e) and (f) is multiplied by factor of 0.2 for comparison with the weak signals from other elements.

combustion conditions at the sources. It was reported that soot with a high content of unburned hydrocarbons would fuse together (Widmann et al., 2003; Leonard et al., 1994). More work on LAC from different sources in East Asia is needed to make any conclusions about origins of the different types discussed here.

For the $1500 \mathrm{~m}$ sample, soot with primary spherules of $30-40 \mathrm{~nm}$ is found on the carbon film substrate (Fig. 4a, b). Mixed states of soot with amorphous carbonaceous spheres are also found (Fig. 4c), similar to the altitude of $120 \mathrm{~m}$ (Fig. 2c). The soot has a turbostratic structure with BSU similar to those from other two altitudes. The mixed status for the particles collected at $1500 \mathrm{~m}$ is reasonable because the longer aging time in the atmosphere increases the probability of collisions and interactions between particles. The EDS (Fig. 4d) result shows the soot has traces of silicon, oxygen, and sulfur. 

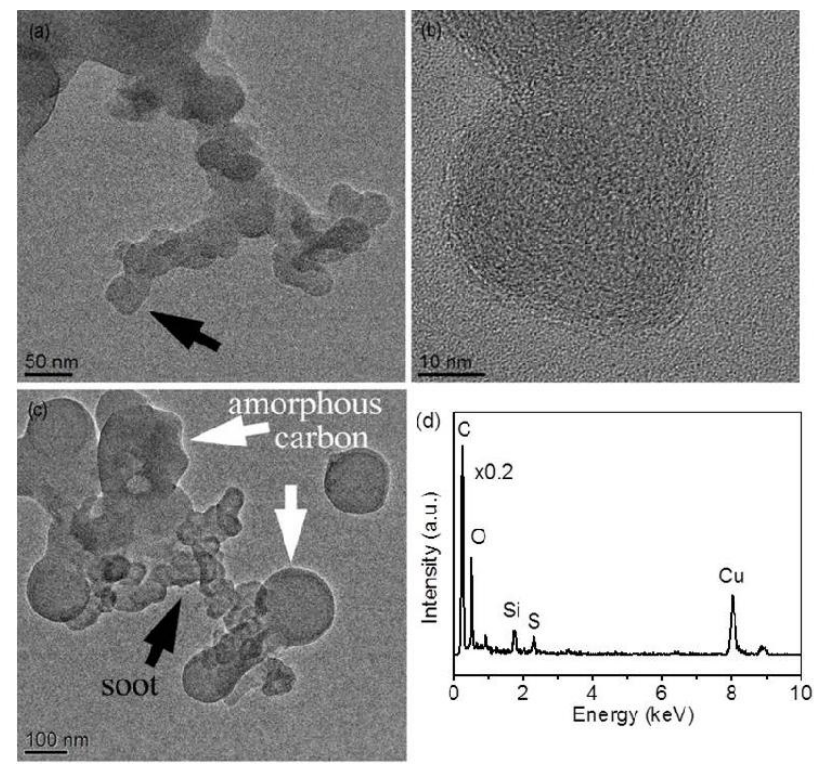

Fig. 4. TEM image (a) of soot collected at $1500 \mathrm{~m}$ and its HRTEM image (b) from the arrowed area. (c) TEM image of soot (black arrow) mixed with amorphous carbonaceous spheres (white arrows). EDS (d) collected from the soot in image (a). The intensity of carbon peak is multiplied by factor of 0.2 for comparison with the weak signals from other elements.

From the EDS results of the soot at the three altitudes, all of them contain mainly carbon. However, some soot at $120 \mathrm{~m}$ may contain oxygen, sulfur, silicon and/or potassium. Some of the soot at $450 \mathrm{~m}$ contains oxygen and silicon, whereas the soot at $1500 \mathrm{~m}$ contains oxygen and sulfur. The potassium suggests some of the soot at $120 \mathrm{~m}$ is from the biomass burning. The soot from the other two altitudes possibly comes from combustion of fossil fuels.

The size distributions and relative number concentrations of primary spherules in soot were determined from a $160 \mu \mathrm{m}^{2}$ area on two low magnification images recorded at two different locations on the grids. The primary spherules in soot attached on other kinds of aerosol particles are also included in the analysis. Figure 5a shows the size distribution of the primary spherules of the soot. Clearly the soot primary spherules at different altitudes have different size distributions. For altitude of 120,450 and $1500 \mathrm{~m}$, their size range is $15-70,20-100$ and $20-60 \mathrm{~nm}$, respectively. The weighted average sizes by number for the primary spherules of the soot are 30,55 and $35 \mathrm{~nm}$ for altitudes of 120,450 and $1500 \mathrm{~m}$, respectively. For altitudes of 120 and $1500 \mathrm{~m}, 70 \%$ of the soot subparticles lies in the range of $20-40 \mathrm{~nm}$ with a unimodal distribution. However, the soot subparticles from $450 \mathrm{~m}$ have a much broader distribution with $70 \%$ of the subparticles lying in the range $30-80 \mathrm{~nm}$. The spherules from $450 \mathrm{~m}$ have a bimodal distribution with peaks at around 35 and $65 \mathrm{~nm}$, respectively.
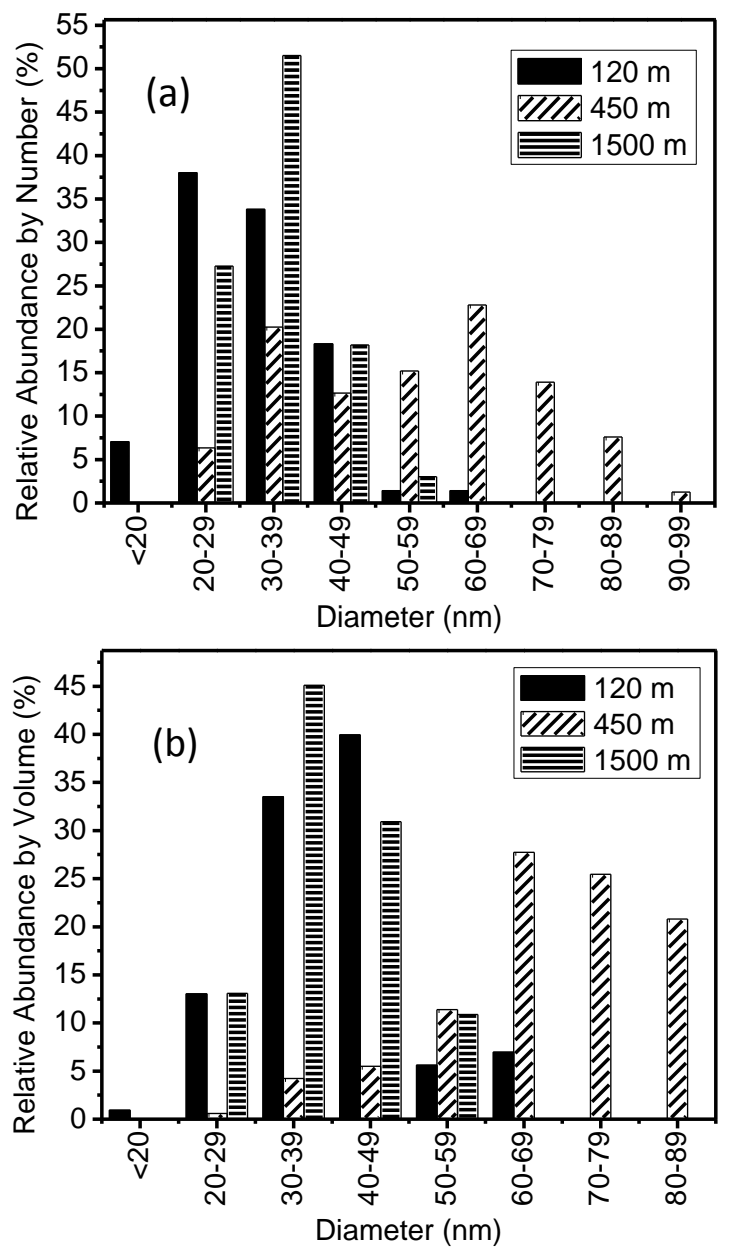

Fig. 5. Relative abundance by number (a) and volume (b) at different diameter for soot primary spherules (not soot particles) collected from three altitudes. The average diameters of the soot spherules weighted by number are 30,55 and $35 \mathrm{~nm}$ for 120,450 and $1500 \mathrm{~m}$, respectively. The average diameters of the soot spherules weighted by volume are 40,70 and $40 \mathrm{~nm}$ for three altitudes.

While it would be useful to know the relative mass concentrations of the different LAC particle types, the densities of the soot and amorphous carbonaceous sphere are unknown and so we have characterized the relative volume concentrations. Figure $5 \mathrm{~b}$ shows the volume distribution with size of the soot spherules at three altitudes. The weighted average sizes by volume for the primary spherules of the soot are 40,70 and $40 \mathrm{~nm}$ for altitudes of 120,450 and $1500 \mathrm{~m}$, respectively. Spherules in $30-50 \mathrm{~nm}$ size range contribute more than $70 \%$ of their total volume at altitude of $120 \mathrm{~m}$. The range changes into $50-85 \mathrm{~nm}$ at altitude of $450 \mathrm{~m}$. For altitude of $1500 \mathrm{~m}$, the soot in range of $30-50 \mathrm{~nm}$ holds more than about $70 \%$ of the total relative volume.

Careful characterization of the primary particle size in the soot aggregates may help in identifying the possible origin of the soot particles (although the existing body of such work is 
far from exhaustive when considering the diversity of combustion sources in a region like East Asia). The primary soot spherules are formed from pyrolysis of volatile organic compounds during combustion. Nuclei first form by condensation during cooling and then grow by additional condensation and then multiple nuclei form aggregates through the coalescence of subparticles. Catalysts are not necessary for the formation of graphitic soot, different from other types of graphitic carbon, like carbon nanotubes (Zhu et al., 2012a, b). Griffin reported that the morphology of the soot is strongly related to their origin (Griffin and Goldberg, 1979). For instance, spherules from certain diesel engines are within a narrow range around $25 \mathrm{~nm}$ with a variation range of $33-36 \%$ in different operating conditions (Lapuerta et al., 2007). However, a larger range of combustion conditions that might be possible has not been addressed yet, even for a single source type such as diesel.

Our results are also consistent with the soot collected from other regions with slight differences. Fu et al. (2008) reported that the spherules from the fuel oil burning at a small city of Tokaimura near the highway were spherical and $50 \mathrm{~nm}$ in size. Coz and Leck (2011) reported freshly formed soot aggregates in Southern Asia had an open branched structure, however, after long-range transport, the soot aggregates became compact with a complex internal mixture, and eventually coated with a layer consisting of organic and inorganic compounds. However, when considering LAC measured at different ground stations when Lagrangian advection conditions cannot be shown, the conclusion of aging may be subject to uncertainty. Most of the reported work focused on the soot with spherules in size range of 20-60 nm. Our finding indicates that typical small spherule soot can have a much broader subparticle size range up to $100 \mathrm{~nm}$. And at certain altitudes, i.e., $450 \mathrm{~m}$, the subparticles in $50-90 \mathrm{~nm}$ size range dominate the whole volume of soot.

\subsection{Amorphous carbonaceous spheres}

Consistent with our previous report (Alexander et al., 2008) on aerosols from a different ACE-Asia flight (RF13 on 23 April 2001 and on the opposite side of a frontal passage from RF14), another significant kind of LAC found at the three altitudes are carbonaceous spheres. The carbonaceous spheres, larger than the soot spherules, are amorphous, and predominantly isolated. As such, they are morphologically similar to the "tar balls" described by Posfai et al. (2004), although the absence of potassium in the carbonaceous spheres in East Asian outflow described here suggests that they may not have the same biomass-burning origin as "tar balls". Morphologically similar spheres have been observed in a variety of settings (e.g., the Phoenix, Arizona urban aerosol as shown by SEM images by Anderson et al. (2006) where biomass burning is an insignificant source), so there may be a variety of such individual carbon spheres. Higher magnification TEM images from these LAC particles for altitudes of 120, 450 and $1500 \mathrm{~m}$ are shown in Figs. 6, 7 and 8, respectively.

At $120 \mathrm{~m}$ altitude, most of the spheres are found mixed with other kinds of aerosol particles. Figure 6a is an amorphous brown carbon sphere mixed with other irregular carbon particles. The dielectric and optical properties of the brown carbon will be discussed in a future paper. Two soot spherules (indicated by arrows) are also found on the surface of the brown carbon. Figure $6 \mathrm{~b}$ is an amorphous carbonaceous sphere touching some shell-like residue which resulted after electron beam irradiation of the original material that may have been organic. To get volume information from the TEM images, we investigated the 3-D particle shape by examining intensity line profiles across the TEM image of particles as shown in Fig. 6 d. The line profiles are the image intensity plotted as a function of position along a line in the images. The intensity will be highest in the vacuum area and will drop on the samples. To a first approximation, the average image intensity from thin amorphous carbon varies linearly with mass thickness. The elliptical profile I of Fig. $6 \mathrm{~d}$ is consistent with a solid 3-D spherical particle. Another sphere is shown in Fig. 6c on top of the TEM carbon film with part suspended over the vacuum. Two line profiles are collected across the sphere. All the three line profiles have different lengths. The profiles are scaled to the same width in Fig. 6 to make it easier to compare their shapes. The profile from the part of the particle suspended over the vacuum is in the form of a smooth elliptical curve, which would be expected from a spherical shaped particle (profile II). However, the other profile from the area of the particle lying partially on the carbon film (profile III) shows discontinuities in the slope at the two ends of the profile (see the arrows) and a relatively constant intensity in the middle. At first glance, a flat profile suggests that the particle may be flattened perhaps as a result of colliding with the carbon film during the sample collecting process. However, further analysis discussed below reveals that this interpretation is not correct and that the particles are indeed spherical in shape.

For samples from altitudes of 450 and $1500 \mathrm{~m}$, most of the amorphous brown carbon spheres on the TEM grids are also found to have the nearly flattened line profile as seen in Fig. 7. In some cases these spheres were found to have tails as shown in Fig. 7b. In contrast to observations at $120 \mathrm{~m}$, the amorphous carbonaceous spheres at $450 \mathrm{~m}$ consisted mostly of isolated particles dispersed on the surface of the carbon film without internal mixing with other aerosol types.

A typical brown carbon particle collected at $1500 \mathrm{~m}$ is shown in Fig. 8a. It is amorphous and its line profile, similar to that in Fig. 7, has a nearly flattened profile. A coatinglike contrast is found on its surface. The sample was tilted over a range of angles and images were recorded to obtain more information about the nature of the coating. As shown in Fig. 8a, b and c, the width of the arrowed edge changed with tilt, which indicated the coating is not continuous over the surface of the particle. The chemical composition of the 

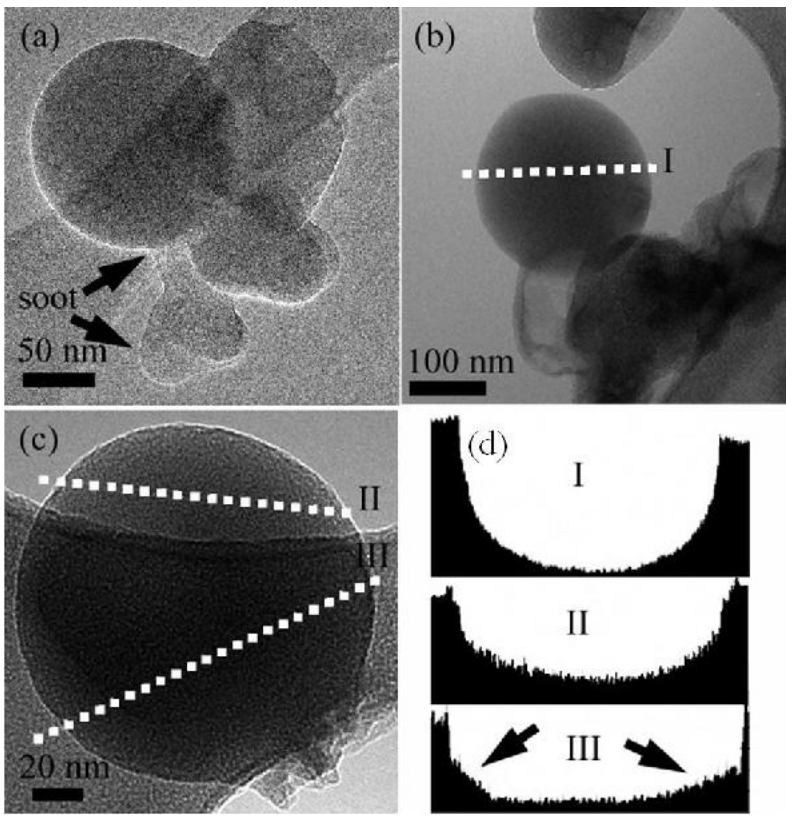

Fig. 6. TEM images of amorphous carbonaceous spheres collected at $120 \mathrm{~m}$. (a) A sphere mixed with soot particles (arrow), and (b) a sphere mixed with possibly organic residue. (c) A sphere on the carbon support film. (d) Line profiles (I, II, III) come from the dashed lines across the spheres in image (b) and (c).
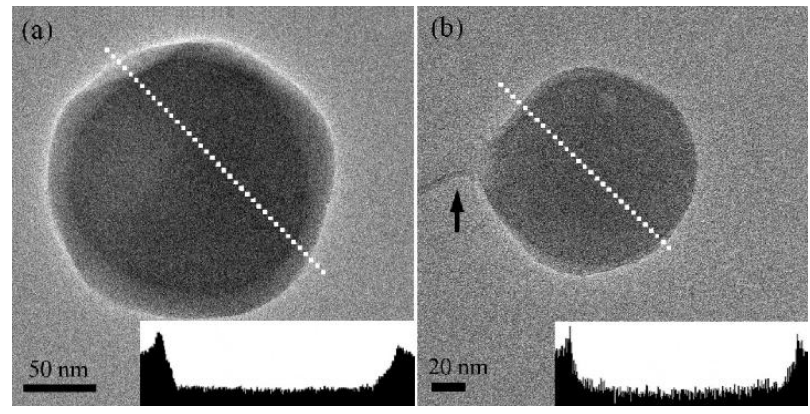

Fig. 7. TEM images of (a) an amorphous carbonaceous sphere collected at $450 \mathrm{~m}$, and (b) another one with a tail (arrow). Insets are the profiles for the dashed line across the spheres.

coating has no detectable difference from the spheres according to EDS. The coating surrounding the spheres is postulated to be a viscous organic layer. Spheres with a tail in the form of a viscous structure were also found. This kind of structure has the same composition as the sphere without tails (Fig. 8d). Both of them contain mainly carbon, oxygen and trace sulfur (Fig. 8f-I). However, the tail also contains a high concentration of potassium (Fig. 8f-II) and could be formed from organic hydrocarbon mixed with a potassium salt. The lack of circular symmetry in these structures implies that this potassium containing organic species was not originally completely coating the sphere but may have been in the form
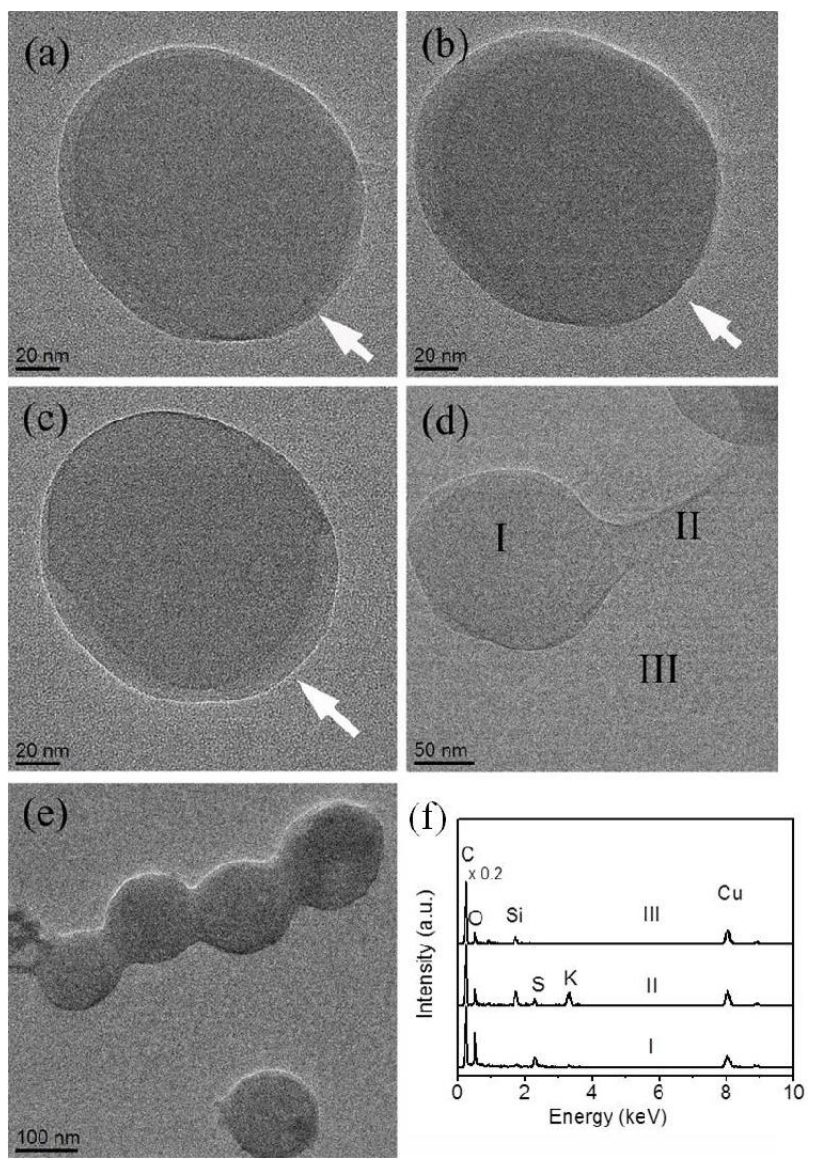

Fig. 8. TEM images of an amorphous carbon sphere (brown carbon) collected at $1500 \mathrm{~m}$, with TEM stage tilted at (a) 0 , (b) 10 , and (c) $-10^{\circ}$. (d) A brown carbon sphere with a tail. (e) Four brown carbon spheres connected together in a line. (f) EDS from three areas inside image (d). The intensity of carbon peak is multiplied by factor of 0.2 for comparison with the weak signals from other elements.

of a small particle attached to the side of the sphere. Most spheres are isolated on the carbon film, however, a small fraction of them are connected together (Fig. 8e), which is likely present in the atmosphere.

EDS spectra of the amorphous spheres at the three altitudes are similar to each other. All contained carbon, oxygen, and minor sulfur and silicon. The amorphous carbonaceous spheres might be from the same type of source, although this is still uncertain. The absence of potassium in the spheres suggests that, unlike the tar balls from the work of Posfai et al. (2004), they are not generated by biomass combustion.

As described in Sect. 2, Beer's absorption law, $I_{t}=$ $I_{0} e^{(-\alpha t)}$, was used to investigate the intensity variation with particle thickness for the imaging conditions employed. As shown in Fig. 9a, the $\ln \left(I_{0} / I_{t}\right)$ versus $t$ curve is linear over a wide size range (here $t$ is the measured diameter of the carbonaceous spheres) and has a slope of $\alpha$. The value of $\alpha$, which varies with different collection angles (Zhang et al., 

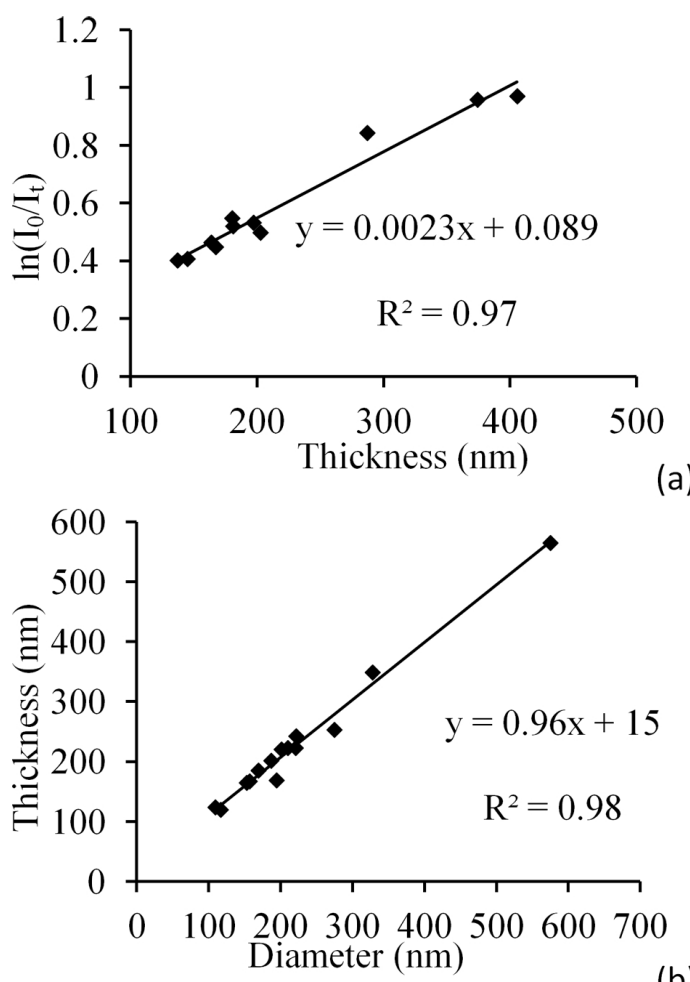

(b)

Fig. 9. (a) Experimental data of $\ln \left(I_{0} / I_{t}\right)$ versus $t$ for absorption coefficient $(\alpha)$ from two samples and their linear fitting with equation and square of the correlation coefficient $R^{2}$. (b) The calculated thickness versus measured diameter of amorphous carbonaceous spheres and their linear fitting with equation and square of the correlation coefficient $R^{2}$. The slope close to 1 indicates their thickness is comparable to their diameter.

2012), is found to be $0.0023 \mathrm{~nm}^{-1}$ under our TEM imaging conditions. It should be pointed out that the data in Fig. 9a are from eleven particles on two holey carbon grids. All the points lie along a straight line suggesting that the method of determining the absorption coefficient $(\alpha)$ is reasonable. We now assume that the amorphous carbonaceous particles on a continuous carbon film grid from the other two altitudes have similar electron scattering strengths and we use the same absorption coefficient $\alpha$ to determine their thickness in the electron beam direction. The calculated thickness versus the measured diameter of the fourteen particles is shown in Fig. 9b. The slope was about 0.96 revealing the thickness is comparable to the measured diameter. So we can conclude that these particles also have a spherical shape and there was negligible plastic deformation during the collision with carbon film. We also simulated the intensity line profile across a spherical sphere on a carbon film using the absorption coefficient $(\alpha)$. The simulated line profiles (not shown) matched the experimental ones, further validating this model.
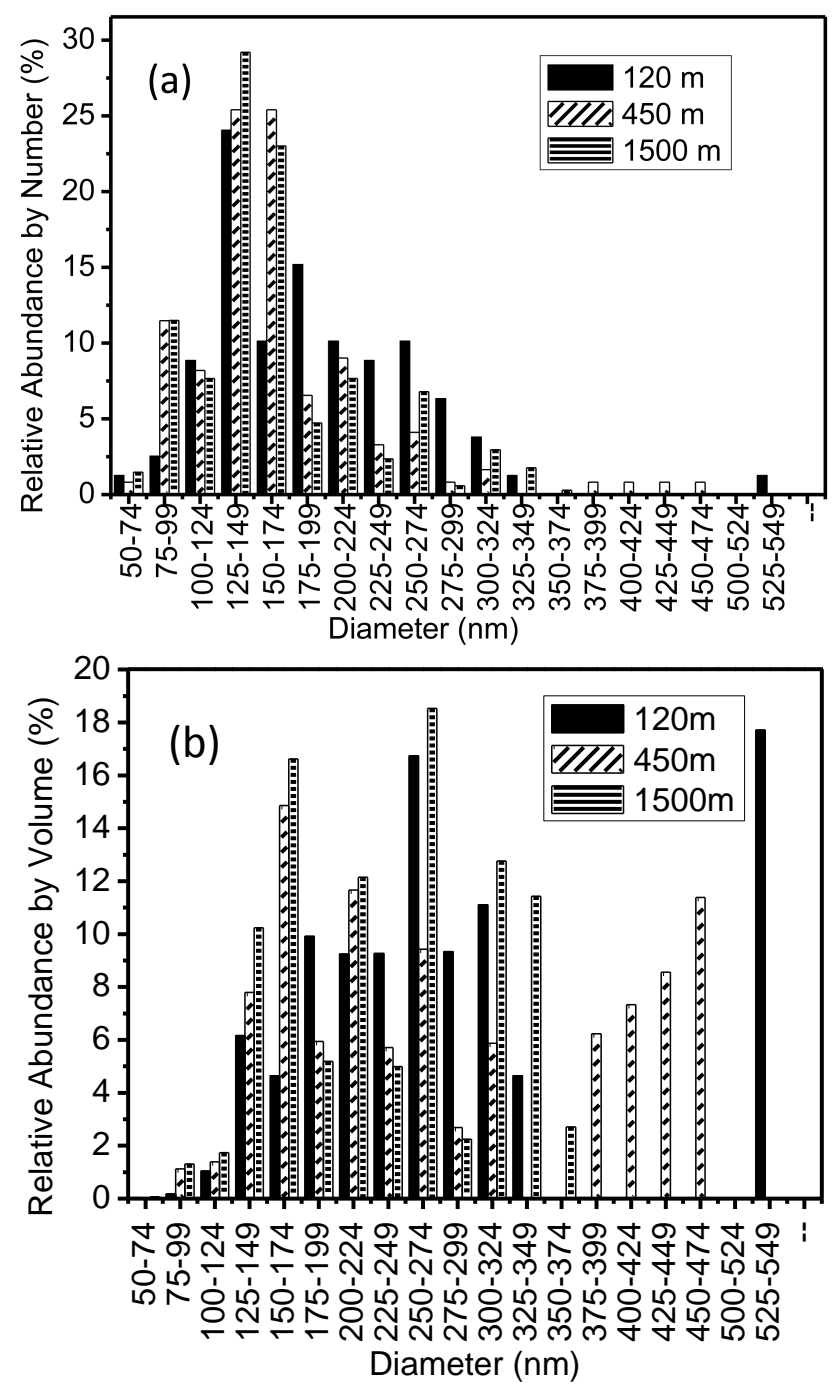

Fig. 10. Relative abundance by number (a) and volume (b) versus diameter for amorphous carbonaceous spheres collected from three altitudes. The relative abundance only considers the brown carbon. The average diameters of the brown carbon spheres weighted by number are 200, 170 and $160 \mathrm{~nm}$ for 120,450 and $1500 \mathrm{~m}$, respectively. The average diameters of the brown carbon spheres weighted by volume are 290,280 and $235 \mathrm{~nm}$ for the three altitudes.

The number and volume distributions of amorphous carbonaceous spheres (Fig. 10) were determined from a $160 \mu \mathrm{m}^{2}$ area (the same area used to analyze the soot) on two low magnification images recorded at two different locations on the grids. The volume calculation depends on the confirmation of the 3-D shape of the particles. The weighted average diameters by number (and by volume) are 200, 170 and $160 \mathrm{~nm}(290,280$, and $235 \mathrm{~nm})$, for altitudes of 120,450 and $1500 \mathrm{~m}$, respectively. The brown carbon spheres at $120 \mathrm{~m}$ are in the range of $50-350 \mathrm{~nm}$ with $70 \%$ of $125-275 \mathrm{~nm}$. About $1 \%$ of the spheres are in the range of $525-550 \mathrm{~nm}$. For $450 \mathrm{~m}$ altitude, the spheres have a large size range of $50-475 \mathrm{~nm}$ 
with about $70 \%$ lying in the $100-225 \mathrm{~nm}$ range. For 1500 $\mathrm{m}$, the spheres range from $50-350 \mathrm{~nm}$ with about $70 \%$ of $100-225 \mathrm{~nm}$. Figure $10 \mathrm{~b}$ shows the volume distribution with the distribution also varying with altitude. At $120 \mathrm{~m}$, spheres of $200-350 \mathrm{~nm}$ contribute about $70 \%$ of the total volume. The small quantity of large spheres above $500 \mathrm{~nm}$ takes about $18 \%$ of the total volume. At $450 \mathrm{~m}, 70 \%$ of the total volume lay in a wide range of $160-470 \mathrm{~nm}$. In contrast, the relatively smaller spheres of $150-325 \mathrm{~nm}$ take about $70 \%$ of the total volume for altitude of $1500 \mathrm{~m}$.

\subsection{Minor types of LAC particles}

In addition to the soot with primary spherule size in the range of $20-100 \mathrm{~nm}$ (which we term small spherule soot) shown in Sect. 3.1, lower concentrations of a soot type made of larger graphitic spherules (Fig. 11) were also found in samples collected at $120 \mathrm{~m}$. This kind of soot has a primary spherule size in the range of 130-230 nm (Fig. 11a). They are termed large spherule soot to differentiate them from the small spherule soot previously described. The large spherule soot is graphitic as shown in the HRTEM image in Fig. 11b and spherules are connected together to give a cylinder-like structure. The volume of large spherule soot is about $29 \times 10^{6} \mathrm{~nm}^{3}$ in an area of $6400 \mu \mathrm{m}^{2}$. Their volume ratio to the small soot in the same area is about 0.11 , comprising about 10 percent of the soot by volume. So, it is necessary to take into account this kind of large spherule soot in spite of its lower concentration. Onion-like small soot spherules with diameters of about $40 \mathrm{~nm}$ were occasionally attached on the surface of the large spherule soot (Fig. 11b). No large spherule soot was found at 450 and $1500 \mathrm{~m}$ altitude in this case; this perhaps suggests the large spherule soot might come from local pollution including ships and fishing boats. However, as discussed in above sections, at the same altitude, the small spherule soot containing potassium was also found. So, it is possible that the small spherule soot was from the biomass burning and the large spherule soot was from the local pollution. The air mass sampled at $120 \mathrm{~m}$ was in the MBL whereas the higher altitudes were in dry continental air. Chen et al. (2005) found similar large spherule soot with primary spherule size of about $100-400 \mathrm{~nm}$ in bituminouscoal-derived samples, but not in samples from diesel or residual oil combustion. Large spherule soot with similar size and morphology has also been observed in the Phoenix, Arizona, aerosol (Anderson et al., 2006) where neither ships nor coal combustion are likely sources. Again, without characterizing the many diverse combustion sources in the region the origin of the various carbonaceous particle types remains uncertain.

Another minor type of LAC are carbon cenopheres, hollow spheres that were also found in another ACE-Asia C-130 flight, RF13 on 23 April 2001 (Clarke et al., 2004) and on ACE-Asia samples collected by research ship (Quinn et al., 2004). On stages 2 and 3 they were observed only at altitudes of 120 and $1500 \mathrm{~m}$. TEM images and their EDS of the ceno-

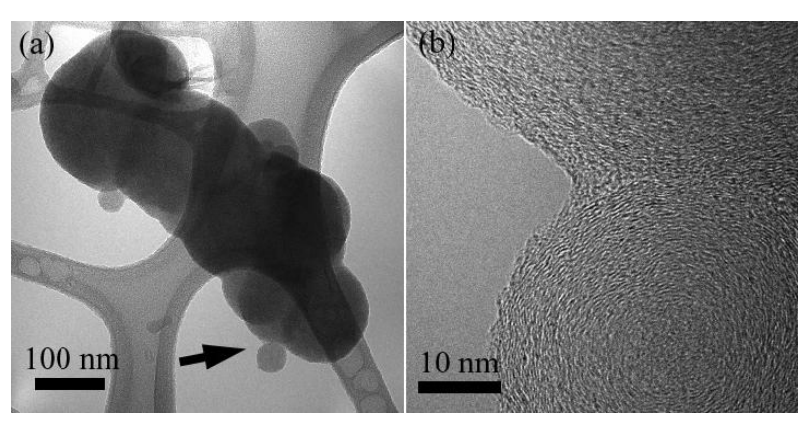

Fig. 11. TEM image (a) of large spherule soot from $120 \mathrm{~m}$, and HRTEM image (b) from the area indicated by arrow.
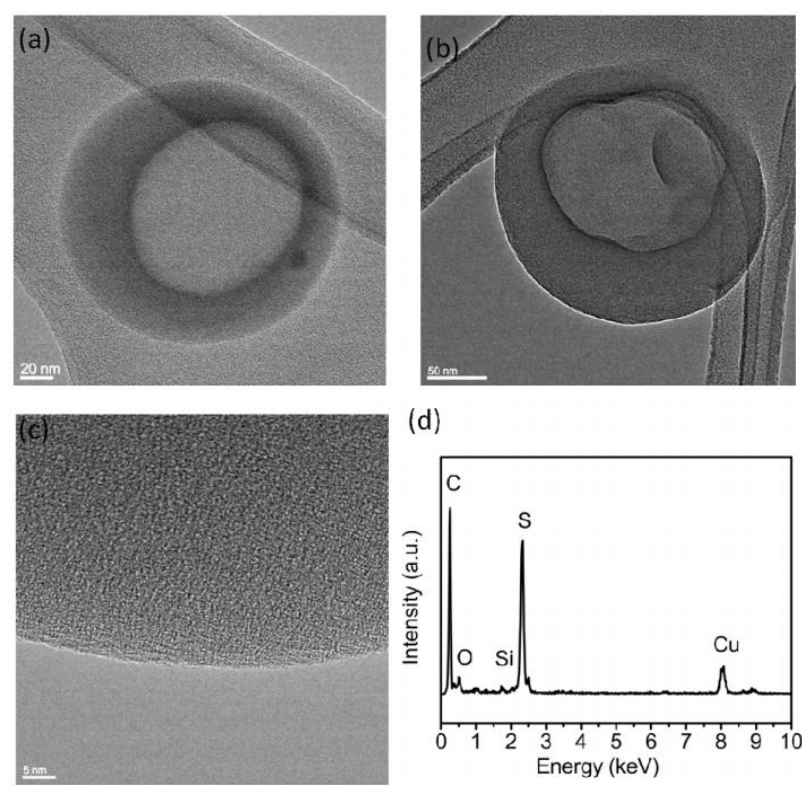

(d)

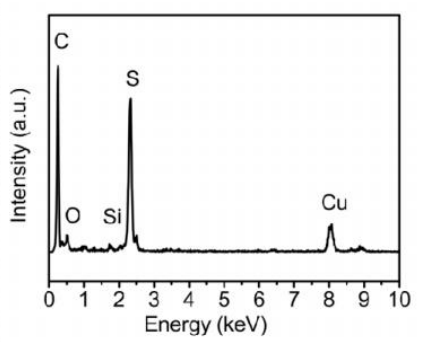

Fig. 12. TEM images of cenospheres with different morphologies collected at $120 \mathrm{~m}$ (stage 2). (a) Inner hollow structure, (b) another hollow structure, (c) the HRTEM image of part of (b). (d) EDS collected from the cenosphere in Fig. 12b.

spheres from an altitude of $120 \mathrm{~m}$ are shown in Fig. 12. From the HRTEM image (Fig. 12c), the cenospheres are amorphous rather than graphitic (Quinn et al., 2004; Clarke et al., 2004). From the contrast of the images, there is an empty space inside the carbon spheres in Fig. 12a and b (as expected). The hollow spheres found at $1500 \mathrm{~m}$ have similar structure and composition with those at $120 \mathrm{~m}$ with diameters in the range of $150-250 \mathrm{~nm}$. The ratio of the inner diameter to outer diameter was relatively constant at around $0.6-0.65$, suggesting that these cenospheres may originate from similar combustion conditions. The cenospheres are a common product of pyrolysis during inefficient combustion of heavy fuel oil (Bertran and Marques, 2004). During the heating of the fuel oil droplet, the gas from the evaporation of lighter compounds surrounds the droplet and burns, which reduces 
Table 2. Number, volume and their ratio in number, and volume of soot and amorphous carbonaceous spheres on $160 \mu \mathrm{m}^{2}$ of the TEM grids at three altitudes.

\begin{tabular}{|c|c|c|c|c|c|c|c|}
\hline \multirow[t]{2}{*}{$\begin{array}{l}\text { Altitude } \\
\text { (m) }\end{array}$} & \multirow[t]{2}{*}{$\begin{array}{l}\text { Collection } \\
\text { time (min) }\end{array}$} & \multicolumn{2}{|l|}{ Soot } & \multicolumn{2}{|c|}{$\begin{array}{l}\text { Amorphous } \\
\text { carbonaceous spheres }\end{array}$} & \multicolumn{2}{|c|}{$\begin{array}{l}\text { Ratio of amorphous } \\
\text { carbonaceous spheres } \\
\text { to soot }\end{array}$} \\
\hline & & Number & $\begin{array}{l}\text { Volume } \\
\left(10^{6} \mathrm{~nm}^{3}\right)\end{array}$ & Number & $\begin{array}{l}\text { Volume } \\
\left(10^{8} \mathrm{~nm}^{3}\right)\end{array}$ & $\begin{array}{l}\text { Number } \\
\text { ratio }\end{array}$ & $\begin{array}{l}\text { Volume } \\
\text { ratio }\end{array}$ \\
\hline 120 & 18 & 294 & 7 & 327 & 18 & 1.1 & 265 \\
\hline 450 & 26 & 79 & 9.5 & 122 & 4.8 & 1.5 & 51 \\
\hline 1500 & 18 & 33 & 0.8 & 339 & 11 & 10.3 & 1400 \\
\hline
\end{tabular}

Table 3. Number and volume concentrations per standard liter of air of silicate dust particles, and amorphous carbon spheres from SEM observations at three altitudes. Using the relative concentration of brown carbon and graphitic soot spherules based on TEM observations, the number and volume concentrations of spherules are also included.

\begin{tabular}{lll|ll|ll}
\hline Altitude $(\mathrm{m})$ & \multicolumn{2}{c|}{ Silicate dust particles } & Amorphous carbonaceous spheres & \multicolumn{2}{c}{ Soot spherules } \\
\cline { 2 - 6 } & Number $\left(10^{5}\right)$ & $\begin{array}{l}\text { Volume }\left(10^{4}\right. \\
\left.\mu \mathrm{m}^{3} \mathrm{~L}^{-1}\right)\end{array}$ & $\begin{array}{l}\text { Number }\left(10^{5}\right) \\
\text { Volume }\left(10^{3}\right. \\
\left.\mu \mathrm{m}^{3} \mathrm{~L}^{-1}\right)\end{array}$ & $\begin{array}{l}\text { Number }\left(10^{4}\right) \\
\text { Volume } \\
\left(\mu \mathrm{m}^{3} \mathrm{~L}^{-1}\right)\end{array}$ \\
\hline 120 & 2.1 & 0.6 & 0.3 & 0.4 & 2.8 & 1.5 \\
450 & 7.5 & 3.4 & 1.1 & 1.0 & 3.1 & 19.7 \\
1500 & 4.5 & 2.4 & 3.9 & 2.4 & 3.8 & 1.7 \\
\hline
\end{tabular}

the contact of oxygen molecules with the oil droplet. Then, the surface of the droplet will pyrolyze quickly and form a solid state carbon as the cenosphere shell. They are very stable under the high electron beam current used in TEM analysis. EDS of the cenospheres indicates they contain high amounts of sulfur besides carbon and traces of silicon. The sulfur is residue from the $\mathrm{SO}_{2}$ gas, which is probably responsible for the formation of the hole. Xie et al. (2007) found the same kind of LAC collected in the marine boundary layer, with spherical shape, porous structure and high sulfur content from residual oil combustion by ship emissions. So the cenospheres may also come from the residual oil combustion. The number of cenospheres is about 5 over an area of $160 \mu \mathrm{m}^{2}$. If we assume the holes inside the particles are spherical, their total volume can be calculated to be about $12 \times 10^{6} \mathrm{~nm}^{3}$. Within the same sampling area, the total number of amorphous carbonaceous spheres was 327 with a corresponding total volume of about $18 \times 10^{8} \mathrm{~nm}^{3}$ (Table 2). Thus the cenospheres are less than $1 \%$ of the total volume and would be negligible for the light absorption in the submicron range of stages 2 and 3. However, much larger cenospheres (up to at least $10 \mu \mathrm{m}$ diameter) are observed by SEM in corresponding single-stage filter samples. The large cenospheres are in very low concentration as measured by SEM and their contribution to bulk optical properties would be correspondingly low. There are higher concentrations of carbon cenospheres in other flights and in those cases their optical effects may be more significant.

\subsection{The statistics of soot and amorphous carbonaceous spheres}

For the size fraction studied by TEM, the total number and volume of primary spherules in soot and separate brown carbon spheres analyzed in the same grid areas are listed in Table 2 in order to evaluate the relative importance of the two major carbonaceous particle types. In all cases, the volume of brown carbon is greater than the volume of soot (as determined by measuring individual spherules), with the most extreme case at $1500 \mathrm{~m}$. The number of soot spherules (but not soot particles, which are comprised of multiple spherules) is similar to the number of brown carbon spheres at $120 \mathrm{~m}$, but only a tenth of the number of brown carbon particles at $1500 \mathrm{~m}$. The number ratio of brown carbon to actual soot particles is even greater. The larger diameters of brown carbon spheres compared to soot spherule diameters combined with the number ratios make brown carbon the dominant carbonaceous particle type in the submicron range for the air masses sampled. Also, the aerosol layers sampled at different altitudes are clearly different with regard to the carbonaceous particle population.

The absolute number and volume concentration of particles per standard liter of air based on SEM observations are shown in Table 3. The number ratios of silicate dust particles to amorphous carbonaceous spheres are about 7, 7 and 1 for altitudes of 120,450 and $1500 \mathrm{~m}$, respectively. While, their volume ratios are 14, 34, 10 for three altitudes. The high concentrations of amorphous carbon spheres (brown carbon) at 
all the three altitudes are consistent with the TEM observations.

\section{Conclusions}

During a research flight above the Yellow Sea on 25 April 2001, several kinds of LAC were observed at sampled altitudes of 120,450 and $1500 \mathrm{~m}$ in a stratified lower troposphere during an outbreak of East Asian dust and pollution. The LAC included high number concentrations of small spherule soot and amorphous carbonaceous spheres (brown carbon) along with lower relative concentrations of large spherule soot and carbon cenospheres in the submicron fraction. The soot at all three altitudes was graphitic, with similar basic structures. The amorphous carbonaceous spheres all had a similar chemical composition in samples from the three altitudes. Image intensity analysis confirmed their spherical shape. The relative number concentration of soot spherules was comparable to that of brown carbon spheres at altitudes of 120 and $450 \mathrm{~m}$. However, the numbers of carbonaceous spheres were ten times that of the soot spherules at $1500 \mathrm{~m}$. Lower number concentrations of large spherule soot with a graphitic structure contributed about $10 \%$ of the soot volume. The amorphous hollow carbon cenospheres were less than $1 \%$ of the volume of the amorphous carbonaceous spheres.

The general conclusion to be drawn from this work is that in a stably stratified troposphere, such as was commonly encountered for East Asian outflow in ACE-Asia, the vertical distribution of LAC types is not homogeneous and therefore the radiative effects of LAC are more complex than if the distribution was more uniform. The presence of an overwhelming majority of LAC present in the form of amorphous brown carbon spheres in outflow above the Yellow Sea in these samples is striking and shows the need for understanding more than just bulk elemental carbon and organic carbon fractions of East Asian aerosols. Another conclusion to be drawn from the vertical variation in aerosol is that sampling from only ground stations is inadequate for determining the radiation forcing effects of pollutant outflow containing light absorbing carbon. It is important to be cautious concerning conclusions about LAC aging based on sampling involving non-Lagrangian advection of what may be different aerosols in a vertically inhomogeneous lower troposphere.

Acknowledgements. The authors acknowledge support of the National Center for Electron Microscopy, Lawrence Berkeley Lab, and the National Institute of Standards and Technology under Award 60NANB10D022. The authors also acknowledge John M.Cowley Center for High Resolution Microscopy at Arizona State University. Participation in ACE-Asia was funded by NSF grant ATM-0002513.

Edited by: D. Topping

\section{References}

Alexander, D. T., Crozier, P. A., and Anderson, J. R.: Brown carbon spheres in East Asian outflow and their optical properties, Science, 321, 833-836, doi:10.1126/science.1155296, 2008.

Anderson, J. R., Buseck, P. R., Patterson, T. L., and Arimoto, R.: Characterization of the Bermuda tropospheric aerosol by combined individual-particle and bulk-aerosol analysis, Atmos. Environ., 30, 319-338, doi:10.1016/1352-2310(95)00170-4, 1996.

Anderson, J. R., Moor, G., Femando, H., and Hyde, P.: A Field Study of Particulate Emissions from Major Roadways in the Phoenix Airshed, Arizona Dept. of Transportation, Phoenix, ATRC Report 495, 101, 2006.

Arimoto, R., Kim, Y. J., Kim, Y. P., Quinn, P. K., Bates, T. S., Anderson, T. L., Gong, S., Uno, I., Chin, M., Huebert, B. J., Clarke, A. D., Shinozuka, Y., Weber, R. J., Anderson, J. R., Guazzotti, S. A., Sullivan, R. C., Sodeman, D. A., Prather, K. A., and Sokolik, I. N.: Characterization of Asian Dust during ACE-Asia, Global Planet. Change, 52, 23-56, doi:10.1016/j.gloplacha.2006.02.013, 2006.

Bertran, C. A. and Marques, C. S. T.: Study of the particulate matter emitted from residual oil combustion and natural gas reburning, J. Braz. Chem. Soc., 15, 548-555, doi:10.1590/s010350532004000400017, 2004.

Chen, Y. Z., Shah, N., Braun, A., Huggins, F. E., and Huffman, G. P.: Electron microscopy investigation of carbonaceous particulate matter generated by combustion of fossil fuels, Energ. Fuel., 19, 1644-1651, doi:10.1021/ef049736y, 2005.

Clarke, A. D., Shinozuka, Y., Kapustin, V. N., Howell, S., Huebert, B., Doherty, S., Anderson, T., Covert, D., Anderson, J., Hua, X., Moore, K. G., McNaughton, C., Carmichael, G., and Weber, R.: Size distributions and mixtures of dust and black carbon aerosol in Asian outflow: Physiochemistry and optical properties, J. Geophys. Res.-Atmos., 109, D15S09, doi:10.1029/2003jd004378, 2004.

Coz, E. and Leck, C.: Morphology and state of mixture of atmospheric soot aggregates during the winter season over Southern Asia-a quantitative approach, Tellus B, 63, 107-116, doi:10.1111/j.1600-0889.2010.00513.x, 2011.

Fu, F. F., Watanabe, K., Shinohara, N., Xu, X. Q., Xu, L. J., and Akagi, T.: Morphological and light-absorption characteristics of individual BC particles collected in an urban seaside area at Tokaimura, eastern central Japan, Sci. Total Environ., 393, 273282, doi:10.1016/j.scitotenv.2008.01.018, 2008.

Gorbunov, B., Baklanov, A., Kakutkina, N., Windsor, H. L., and Toumi, R.: Ice nucleation on soot particles, J. Aerosol. Sci., 32, 199-215, doi:10.1016/s0021-8502(00)00077-x, 2001.

Griffin, J. J. and Goldberg, E. D.: Morphologies and origin of elemental carbon in the environment, Science, 206, 563-565, doi:10.1126/science.206.4418.563, 1979.

Hansen, J., Sato, M., and Ruedy, R.: Radiative forcing and climate response, J. Geophys. Res.-Atmos., 102, 6831-6864, doi:10.1029/96jd03436, 1997.

Hawkins, L. N., Russell, L. M., Twohy, C. H., and Anderson, J. R.: Uniform particle-droplet partitioning of 18 organic and elemental components measured in and below DYCOMS-II stratocumulus clouds, J. Geophys. Res.-Atmos., 113, D15S09, doi:10.1029/2007jd009150, 2008.

Huebert, B. J., Howell, S. G., Covert, D., Bertram, T., Clarke, A., Anderson, J. R., Lafleur, B. J., Seebaugh, W. R., Wil- 
son, J. C., Gesler, D., Blomquist, B., and Fox, J.: PELTI: Measuring the passing efficiency of an airborne low turbulence aerosol inlet, Aerosol Sci. Tech., 38, 803-826, doi:10.1080/027868290500823, 2004.

Koch, D. and Del Genio, A. D.: Black carbon semi-direct effects on cloud cover: review and synthesis, Atmos. Chem. Phys., 10, 7685-7696, doi:10.5194/acp-10-7685-2010, 2010.

Lapuerta, M., Martos, F. J., and Herreros, J. M.: Effect of engine operating conditions on the size of primary particles composing diesel soot agglomerates, J. Aerosol Sci., 38, 455-466, doi:10.1016/j.jaerosci.2007.02.001, 2007.

Lary, D. J., Lee, A. M., Toumi, R., Newchurch, M. J., Pirre, M., and Renard, J. B.: Carbon aerosols and atmospheric photochemistry, J. Geophys. Res.-Atmos., 102, 3671-3682, doi:10.1029/96jd02969, 1997.

Leonard, S., Mulholland, G. W., Puri, R., and Santoro, R. J.: Generation of $\mathrm{CO}$ and smoke during underventilated combustion, Combust. Flame, 98, 20-34, doi:10.1016/0010-2180(94)901953, 1994.

Li, W. J., Shao, L. Y., and Buseck, P. R.: Haze types in Beijing and the influence of agricultural biomass burning, Atmos. Chem. Phys., 10, 8119-8130, doi:10.5194/acp-10-8119-2010, 2010.

Liu, Y. C., Liu, C., Ma, J. Z., Ma, Q. X., and He, H.: Structural and hygroscopic changes of soot during heterogeneous reaction with O-3, Phys. Chem. Chem. Phys., 12, 10896-10903, doi:10.1039/c0cp00402b, 2010.

Monge, M. E., D’ Anna, B., Mazri, L., Giroir-Fendler, A., Ammann, M., Donaldson, D. J., and George, C.: Light changes the atmospheric reactivity of soot, P. Natl. Acad. Sci. USA, 107, 66056609, doi:10.1073/pnas.0908341107, 2010.

Pierce, J. R., Chen, K., and Adams, P. J.: Contribution of primary carbonaceous aerosol to cloud condensation nuclei: processes and uncertainties evaluated with a global aerosol microphysics model, Atmos. Chem. Phys., 7, 5447-5466, doi:10.5194/acp-75447-2007, 2007.

Posfai, M., Gelencser, A., Simonics, R., Arato, K., Li, J., Hobbs, P. V., and Buseck, P. R.: Atmospheric tar balls: Particles from biomass and biofuel burning, J. Geophys. Res.-Atmos., 109, D06213, doi:10.1029/2003jd004169, 2004.

Quinn, P. K., Coffman, D. J., Bates, T. S., Welton, E. J., Covert, D. S., Miller, T. L., Johnson, J. E., Maria, S., Russell, L., Arimoto, R., Carrico, C. M., Rood, M. J., and Anderson, J.: Aerosol optical properties measured on board the Ronald H. Brown during ACE-Asia as a function of aerosol chemical composition and source region, J. Geophys. Res.-Atmos., 109, D19S01, doi:10.1029/2003jd004010, 2004.

Ramanathan, V. and Carmichael, G.: Global and regional climate changes due to black carbon, Nat. Geosci., 1, 221-227, doi:10.1038/ngeo156, 2008.

Rodriguez-Fortea, A., Iannuzzi, M., and Parrinello, M.: Ab initio molecular dynamics study of heterogeneous nitric acid decomposition reactions on graphite surfaces, J. Phys. Chem. C, 111, 2251-2258, doi:10.1021/jp066581h, 2007.

Saathoff, H., Naumann, K. H., Schnaiter, M., Schock, W., Mohler, O., Schurath, U., Weingartner, E., Gysel, M., and Baltensperger, U.: Coating of soot and (NH4)(2)SO4 particles by ozonolysis products of alpha-pinene, J. Aerosol. Sci., 34, 1297-1321, doi:10.1016/s0021-8502(03)00364-1, 2003.
Spracklen, D. V., Carslaw, K. S., Pöschl, U., Rap, A., and Forster, P. M.: Global cloud condensation nuclei influenced by carbonaceous combustion aerosol, Atmos. Chem. Phys., 11, 9067-9087, doi:10.5194/acp-11-9067-2011, 2011.

Stith, J. L., Twohy, C. H., DeMott, P. J., Baumgardner, D., Campos, T., Gao, R., and Anderson, J.: Observations of ice nuclei and heterogeneous freezing in a Western Pacific extratropical storm, Atmos. Chem. Phys., 11, 6229-6243, doi:10.5194/acp-11-62292011, 2011.

Twohy, C. H. and Anderson, J. R.: Droplet nuclei in nonprecipitating clouds: composition and size matter, Environ. Res. Lett., 3, 045002, doi:10.1088/1748-9326/3/4/045002, 2008.

Twohy, C. H., Hudson, J. G., Yum, S. S., Anderson, J. R., Durlak, S. K., and Baumgardner, D.: Characteristics of cloud-nucleating aerosols in the Indian Ocean region, J. Geophys. Res.-Atmos., 106, 28699-28710, doi:10.1029/2000jd900779, 2001.

Widmann, J., Yang, J. C., Smith, T. J., Manzello, S. L., and Mulholland, G. W.: Measurement of the optical extinction coefficients of postflame soot in the infrared, Combust. Flame, 134, 119-129, doi:10.1016/s0010-2180(03)00089-0, 2003.

Wyslouzil, B. E., Carleton, K. L., Sonnenfroh, D. M., Rawlins, W. T., and Arnold, S.: Observation of hydration of single, modified carbon aerosols, Geophys. Res. Lett., 21, 2107-2110, doi:10.1029/94gl01588, 1994.

Xie, Z. Q., Blum, J. D., Utsunomiya, S., Ewing, R. C., Wang, X. M., and Sun, L. G.: Summertime carbonaceous aerosols collected in the marine boundary layer of the Arctic Ocean, J. Geophys. Res.Atmos., 112, D02306, doi:10.1029/2006jd007247, 2007.

Zhang, H. R., Egerton, R. F., and Malac, M.: Local thickness measurement through scattering contrast and electron energy-loss spectroscopy, Micron, 43, 8-15, doi:10.1016/j.micron.2011.07.003, 2012.

Zhang, R. Y., Khalizov, A. F., Pagels, J., Zhang, D., Xue, H. X., and McMurry, P. H.: Variability in morphology, hygroscopicity, and optical properties of soot aerosols during atmospheric processing, P. Natl. Acad. Sci. USA, 105, 10291-10296, doi:10.1073/pnas.0804860105, 2008.

Zhu, J. T., Jia, J. C., Kwong, F. L., and Ng, D. H. L.: Synthesis of bamboo-like carbon nanotubes on a copper foil by catalytic chemical vapor deposition from ethanol, Carbon, 50, 2504-2512, doi:10.1016/j.carbon.2012.01.073, 2012a.

Zhu, J. T., Jia, J. C., Kwong, F. L., Ng, D. H. L., and Crozier, P. A.: Metal-free synthesis of carbon nanotubes filled with calcium silicate, Carbon, 50, 2666-2669, doi:10.1016/j.carbon.2012.01.071, 2012 b.

Zhu, J. T., Jia, J. C., Kwong, F. L., Ng, D. H. L., and Tjong, S. C.: Synthesis of multiwalled carbon nanotubes from bamboo charcoal and the roles of minerals on their growth, Biomass Bioenerg., 36, 12-19, doi:10.1016/j.biombioe.2011.08.023, 2012 c. 